\title{
OJS

\section{A EXPERIÊNCIA DO ESTÁGIO DOCENTE EM GEOGRAFIA NA ESCOLA FAMÍLIA AGRÍCOLA JEAN HÉBETTE NO MUNICÍPIO DE MARABÁ/PA}

\author{
Gabriel Renan Neves Barros ${ }^{1}$, Alan Bizerra Martins ${ }^{2}$, Kassia Raylene Sousa da Silva ${ }^{3}$
}

\begin{abstract}
${ }^{1}$ Professor EBTT de Geografia do Instituto Federal do Pará. E-mail: gabriel.barros@ifpa.edu.br - ORCID iD: http://orcid.org/0000-0002-2253-8894

${ }^{2}$ Graduando em Geografia na modalidade Licenciatura da Universidade Federal do Sul e Sudeste do Pará. Email: alanmartinsgeo14@gmail.com - ORCID iD: http://orcid.org/0000-0002-2253-8894

${ }^{3}$ Graduanda em Geografia na modalidade Licenciatura da Universidade Federal do Sul e Sudeste do Pará. Email: raysousasilva@gmail.com - ORCID iD: http://orcid.org/0000-0002-2253-8894
\end{abstract}

Artigo recebido em 29/02/2020 e aceito em 06/04/2020

\begin{abstract}
RESUMO
Este relato de experiência produzido após a realização do estágio docente visa compreender como podemos avançar para um Ensino de Geografia voltado para a Educação do Campo. Para tal, realizou-se na Escola Família agrícola Jean Hébette, localizada no município de Marabá-PA a disciplina de Estágio Docente III. A disciplina foi ofertada entre os meses de outubro de 2017 a março de 2018. A ementa da disciplina nos permitiu trabalhar esta etapa do estágio em escolas com propostas pedagógicas diferentes daquelas já trabalhadas no Estágio Docente I (Ensino Fundamental II) e no Estágio Docente II (Ensino Médio). Esta experiência teve a colaboração do Prof. Me. Marcelo Gaudêncio Brito Pureza (coordenador de estágio), da Prof. Dr. ${ }^{a}$ Élida Pasini Tonetto, do Prof. Me. Gabriel Renan Neves Barros e da Prof. a Ana Lenira Nunes Cysne de Souza. Optamos por duas escolas que ofertam diferentes modalidades de ensino, que são as modalidades da Educação do Campo e da Educação Indígena. Foram escolhidas a Escola Família Agrícola Prof. Jean Hébette, localizada no km 23 da BR-230 (Transamazônica), no município de Marabá/PA e a Escola Indígena Estadual Ensino Fundamental e Médio Tatakti Kyikatêjê, localizado na Aldeia Kyikatêjê. A EFA é uma Escola Municipal de Ensino Fundamental integrada a Rede Ensino da Secretaria Municipal de Educação de Marabá (SEMED) e é sobre a experiência do estágio nesta escola que depreendemos esta pesquisa.

Palavras-chave: Educação do Campo; Ensino de Geografia; Estágio Docente; Currículo; Alternância pedagógica.
\end{abstract}

\section{THE EXPERIENCE OF THE TEACHING STAGE IN GEOGRAPHY AT THE FAMILY AGRICULTURAL SCHOOL JEAN HÉBETTE, IN THE MUNICIPALITY OF MARABÁ / PA}

\begin{abstract}
This experience report produced after the completion of the teaching internship aims to understand how we can move towards Geography Teaching focused on Rural Education. To this end, it was held at the Escola Família agricultural Jean Hébette, located in the municipality of Marabá-PA, the discipline of Teaching Internship III. The course was offered between October 2017 and March 2018. The course's menu allowed us to work on this stage of the internship in schools with pedagogical proposals different from those already worked in Teaching Internship
\end{abstract}


I (Elementary School II) and Teaching Internship II (High school). This experience had the collaboration of Prof. Me. Marcelo Gaudêncio Brito Pureza (internship coordinator), from Prof. Dr. Élida Pasini Tonetto, from Prof. Me. Gabriel Renan Neves Barros and Prof. Ana Lenira Nunes Cysne de Souza. We chose two schools that offer different teaching modalities, which are Rural Education and Indigenous Education. The Escola Família Agrícola Prof. Jean Hébette, located at km 23 of BR-230 (Transamazônica), in the municipality of Marabá / PA and the Tatakti Kyikatêjê State Indigenous School Elementary and High School, located in Kyikatêjê Village. EFA is a Municipal Elementary School integrated into the Teaching Network of the Municipal Education Secretariat of Marabá (SEMED) and it is about the experience of the internship at this school that we understand this research. Keywords: Rural Education; Geography teaching; Teaching Internship; Curriculum; Pedagogical alternation.

\section{INTRODUÇÃO}

A Universidade Federal do Sul e Sudeste do Pará (Unifesspa), por meio da Faculdade de Geografia, oferta em seu curso de licenciatura em Geografia as disciplinas de Estágio Docente, que se caracteriza em uma atividade curricular obrigatória, que visa garantir a profissionalização e compreende 408 (quatrocentos e oito) horas a serem desenvolvidas nos $5^{\circ}$, $6^{\circ}$ e $7^{\circ}$ períodos, distribuído em três atividades de estágio: Estágio Docente I, II e III, de acordo com as ementas e a Resolução CNE/CP n. ${ }^{\circ}$ 2, de 01 de julho de 2015.

O Estágio Docente é mais uma oportunidade que o estudante de licenciatura tem de colocar em prática as teorias aprendidas na graduação e vivenciar previamente a realidade escolar. É um momento de experiências e práticas educacionais. "O estágio é o eixo central na formação de professores, pois, é através dele que o profissional conhece os aspectos indispensáveis para a formação da construção da identidade e dos saberes do dia-a-dia" (Pimenta e Lima, 2004, p. 127).

O estágio é uma forma de aproximação do aluno estagiário com a docência, os principais benefícios consistem na aproximação com a sala de aula em ambiente escolar e não escolar, e a possibilidade de estar em contato direto com esses alunos. $\mathrm{O}$ aluno estagiário observa as aulas ministradas pelo professor regente, e posteriormente, ocorre a regência. Conforme Bezerra:

\footnotetext{
Quando experimentamos o estágio de outra forma, quando não buscamos apenas informações e opiniões sobre a escola, a sala de aula e a Geografia que se ensina, mas tentamos contextualizar, histórico e espacialmente os processos, as diferentes culturas e temporalidades que caracterizam a Escola e a Universidade conseguimos perceber os desafios, as potencialidades e as possibilidades que o cotidiano escolar apresenta. (BEZERRA, 2013, p.44).
}

A disciplina de Estágio Docente III foi ofertada para três turmas. Duas turmas de Licenciatura e Bacharelado em Geografia e uma turma de Licenciatura em Geografia. A 
disciplina foi ofertada entre os meses de outubro de 2017 a março de 2018. A ementa da disciplina nos permite trabalhar esta etapa do estágio em escolas com propostas pedagógicas diferentes daquelas já trabalhadas no Estágio Docente I (Ensino Fundamental II) e no Estágio Docente II (Ensino Médio).

Eram responsáveis pelas disciplinas os seguintes professores(as): Prof. Me. Marcelo Gaudêncio Brito Pureza (coordenador de estágio), Prof. Dr. a Élida Pasini Tonetto, Prof. Me. Gabriel Renan Neves Barros e a Prof. a Ana Lenira Nunes Cysne de Souza. Optamos por duas escolas que ofertam diferentes modalidades de ensino, que são as modalidades da Educação do Campo e da Educação Indígena. Foram escolhidas a Escola Família Agrícola Prof. Jean Hébette, localizada no km 23 da BR-230 (Transamazônica), no município de Marabá/PA e a Escola Indígena Estadual Ensino Fundamental e Médio Tatakti Kyikatêjê, localizado na Aldeia Kyikatêjê. A EFA é uma Escola Municipal de Ensino Fundamental integrada a Rede Ensino da Secretaria Municipal de Educação de Marabá (SEMED) e é sobre a experiência do estágio nesta escola que depreendemos esta pesquisa.

O objetivo geral da pesquisa é compreender a importância do Estágio Docente III para formação acadêmica do graduando em Geografia na Unifesspa, a fim de entender as perspectivas de atuação do futuro docente na Educação Básica das escolas do Campo, bem como a importância da realização desta etapa na EFA.

Os objetivos específicos são: reconhecer a importância do Estágio Docente III para formação do licenciado em Geografia; explicar como foi desenvolvida esta etapa do estágio; justificar a continuidade desta etapa e sua contribuição para a EFA;

A metodologia empregada para responder aos objetivos em questão, desenvolvemos uma análise documental, seguido estudo de caso. Segundo Gil (2008) o estudo de caso aponta alguns propósitos que se enquadram em nossa pesquisa, são eles: 1) explorar situações da vida real cujos limites não estão claramente definidos; 2) preservar o caráter unitário do objeto estudado; 3) descrever a situação do contexto em que está sendo feita uma determinada investigação. Analisamos documentos primordiais para a continuidade desta pesquisa, como o que fundamenta o Estágio Docente no Ministério da Educação (MEC) e outros documentos laborados pela Universidade e pela Faculdade de Geografia e os relatórios de estágio que foram entregues pelos alunos. 
Caracterização da área de estudo

Escola Família Agrícola (EFA) Jean Hébette (figura 01) está localizada no Km 23, Rodovia BR 230 - Transamazônica (sentido Itupiranga), no município de Marabá/PA. A área total da escola equivale a 30 hectares de Terra. A Escola Família Agrícola Jean Hébette atende alunos dos municípios de: Novo Repartimento, Marabá, São Domingos, Eldorado dos Carajás, São João do Araguaia, e a vila Quatro bocas.

Figura 01: Localização da escola.

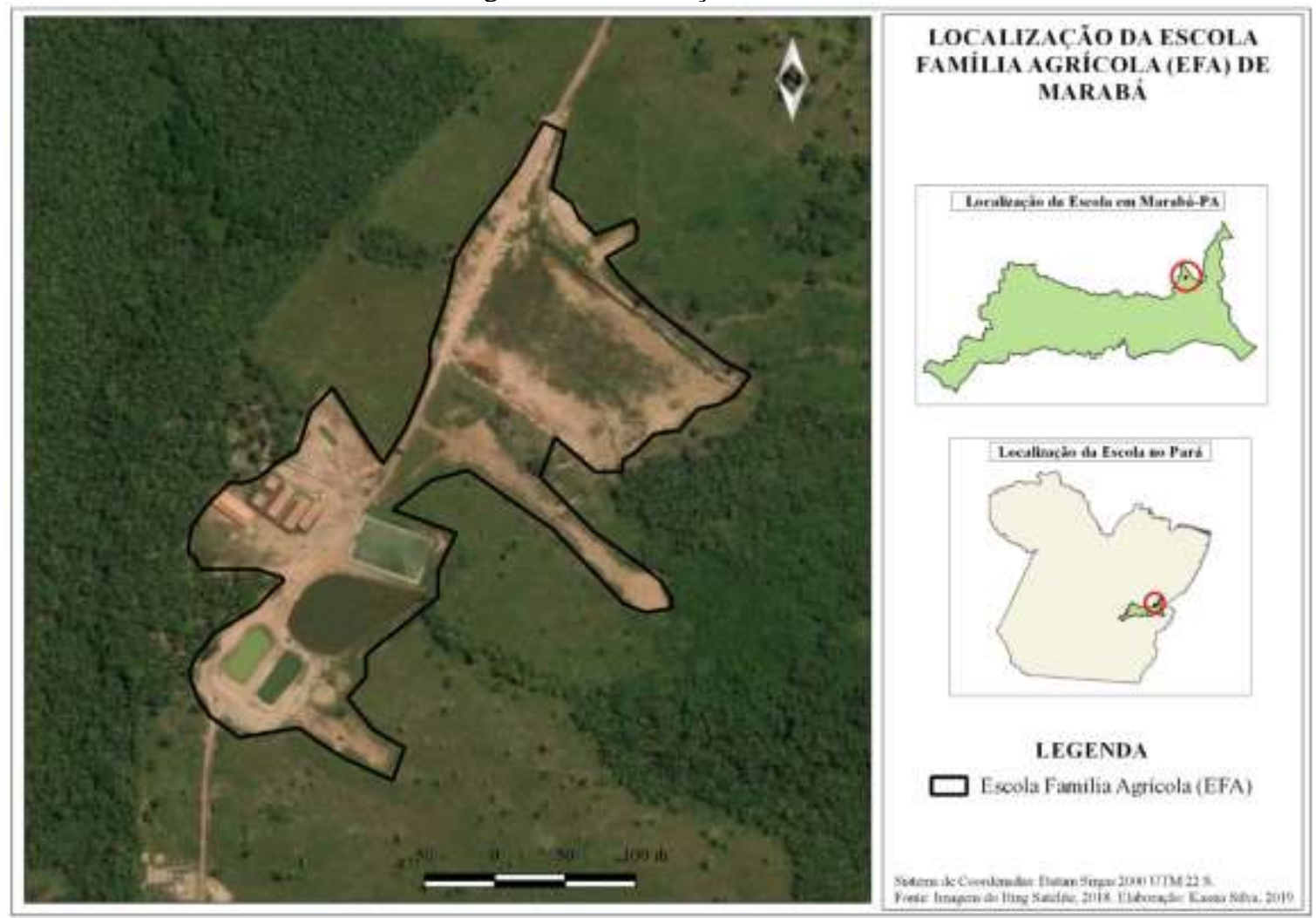

Fonte: Silva, 2018

A Escola Família Agrícola (EFA) de Marabá, é uma instituição pública da rede municipal de ensino que funciona em tempo integral, em regime de internato, onde os alunos ficam 12 dias na escola e alterna em suas comunidades. A escola trabalha a partir da pedagogia da alternância, em que os alunos usam o que lhes foi ensinado em suas comunidades, através de acompanhamento pedagógico. Durante o tempo escola, o professor trabalha com os alunos as disciplinas a partir do tema gerador, que é o tema geral sobre o qual todos os professores irão desenvolver suas aulas. O principal foco da escola é trabalhar a educação em uma perspectiva 
do Campo. Em relação à alimentação, além dos municípios de Novo Repartimento e Marabá ajudarem, há produção própria para subsistência, como criação de suínos, galinhas, produção em horta, etc.

Segundo Almeida (2016) a Escola Família Agrícola (EFA) surgiu nos anos de 1990, no contexto do avanço neoliberal de políticas de privatizações. Nasceu em uma intensa disputa pela terra, para atender jovens e adultos do campo. A EFA integrou várias ações geradas a partir do Centro Agroambiental do Tocantins (CAT), experiência animada por Jean Hébette, um educador natural da Bélgica. A EFA opera a partir da Pedagogia da Alternância, que valoriza vivências a partir do tempo escola e tempo comunidade. Augusto Freire é uma das inspirações, em que o diálogo e a horizontalidade na relação educador-educando ocupam o primeiro plano.

Segundo Zimmermann; Vendruscolo e Dorneles (2013), a Pedagogia da Alternância surgiu na década de 1930, na França, em um contexto de transformações econômicas e sociais, principalmente na agricultura, e onde jovens precisavam deixar o campo e a família para seguir em busca de uma formação. A partir disso, um pequeno grupo de agricultores franceses viram a possibilidade de uma educação que atende às necessidades dos jovens do campo.

Um dos fundadores da EFA e, também o primeiro monitor, foi Damião Santos, que tem formação em Pedagogia da Alternância, é graduado em Pedagogia e especialista em Educação do Campo, é também mestrando de Desenvolvimento Socioespacial e Regional (UEMA).

São duas salas de aulas, mas na prática, uma área aberta também tem essa função, como vemos na figura 02 .

Figura 02: Sala de aula ao ar livre.

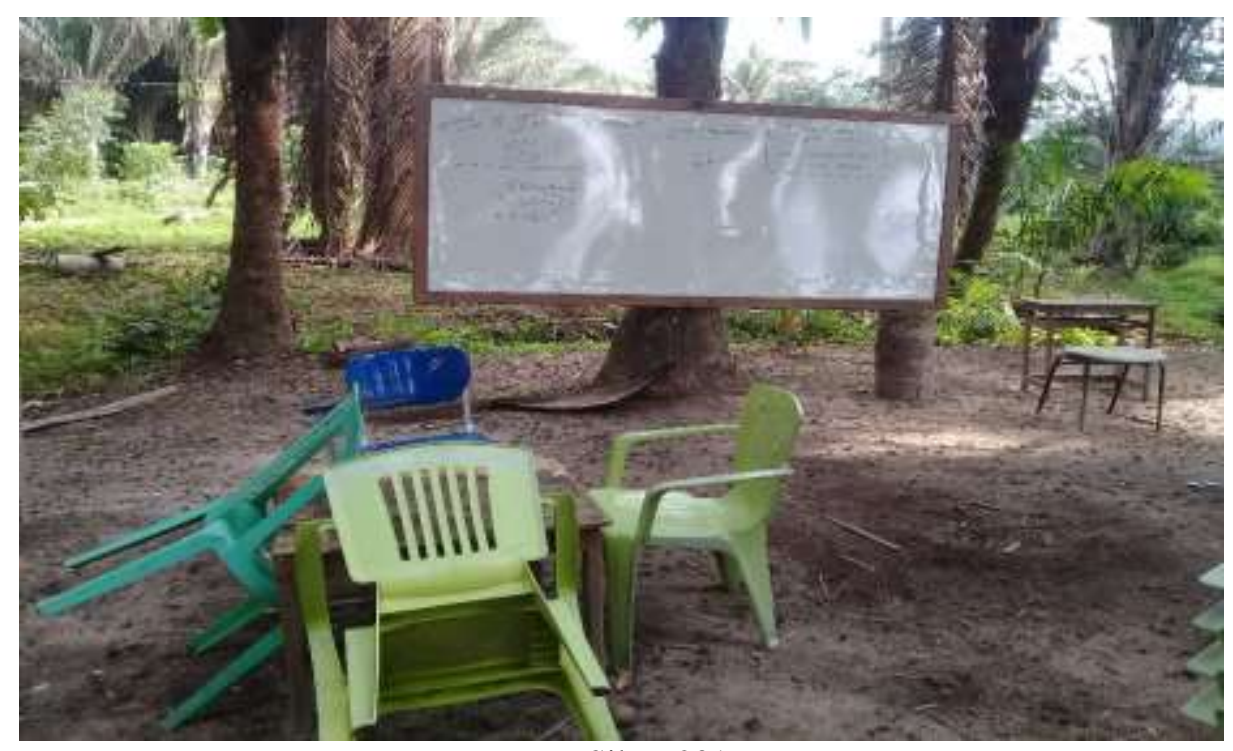

Fonte: Silva, 2017. 
A biblioteca (figura 03) tem um acervo com 1000 livros, também funciona em uma área aberta da escola, não possui um responsável de fato, mas há uma responsabilidade coletiva. Não há sala para os professores, eles ficam nas áreas da escola. Também não há sala de vídeo, quando é necessário o uso de vídeo, é utilizado o auditório, que é usado sempre que necessário. Quanto ao Plano Político Pedagógico da escola, a informação foi que ele estava em processo de reformulação.

Figura 03: Biblioteca.

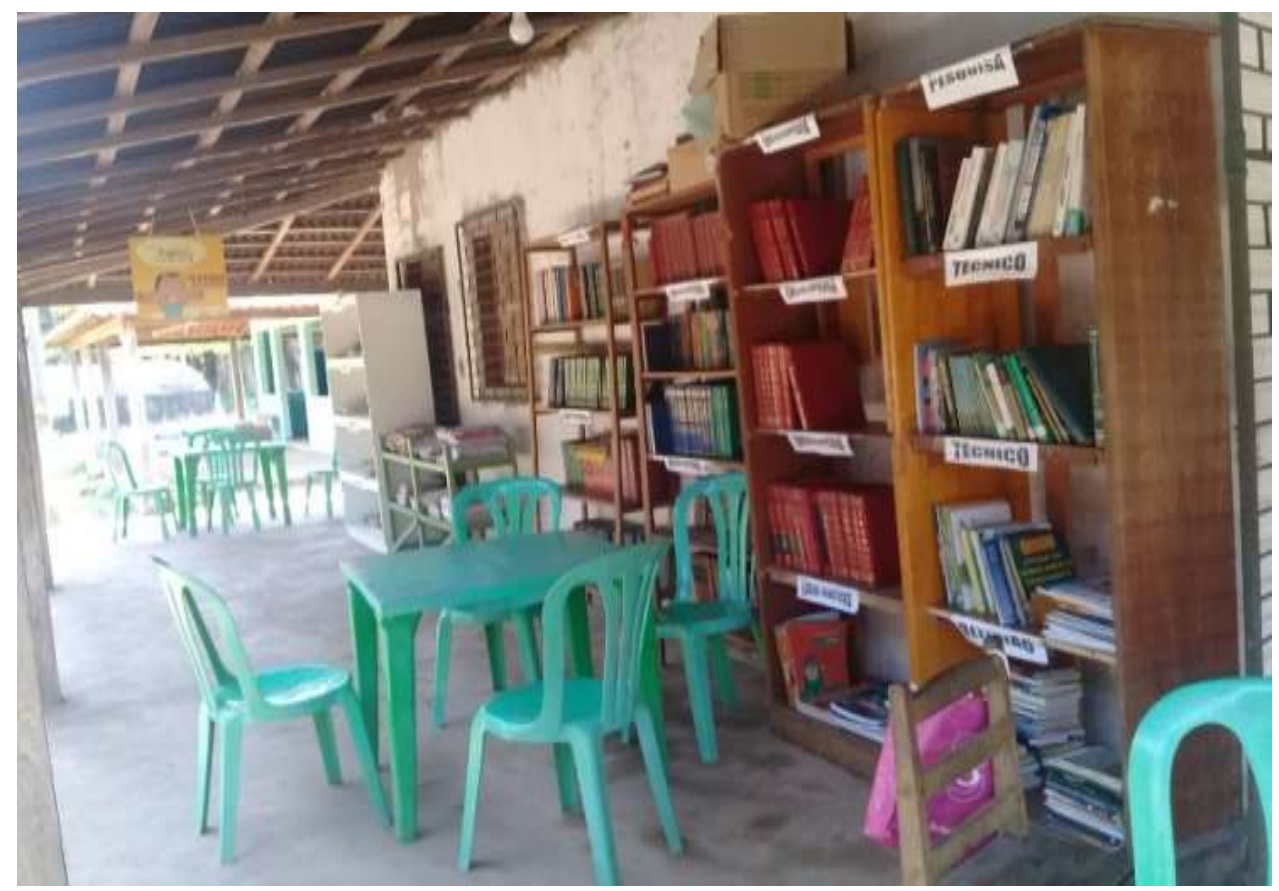

Fonte: Silva, 2017.

No quadro 01, apresentamos a caracterização geral da escola:

Quadro 01: Dados gerais da escola.

\begin{tabular}{|l|l|}
\hline \multicolumn{1}{|c|}{ Informações } & \multicolumn{1}{c|}{ Quantidade } \\
\hline Alunos & 75 \\
\hline Salas de aula & 2 \\
\hline Alunos por sala & $20 /$ em média \\
\hline Professores por disciplina & 2 \\
\hline Coordenador pedagógico & 1 \\
\hline Funcionários & 17 \\
\hline
\end{tabular}




\begin{tabular}{|l|l|}
\hline Carteiras & 100 \\
\hline Ar-condicionado & 0 \\
\hline Sala dos professores & 0 \\
\hline Laboratório de informática & 0 \\
\hline Sala de vídeo & 0 \\
\hline Sala de reprografia & 0 \\
\hline Refeitório & 1 \\
\hline Sala de coordenação & 1 \\
\hline Professores & 8 \\
\hline Orientador pedagógico & 0 \\
\hline Ventilador & 0 \\
\hline Internet & 0 \\
\hline Acervo da biblioteca & 1000 \\
\hline Servidor readaptado (biblioteca) & 0 \\
\hline Sala de reprografia & 0 \\
\hline
\end{tabular}

Organização: Silva, 2018.

A escola possui criação de galinhas (a), produção de hortaliças (b), (c) e (f), piscicultura para criação de peixes (d), criação de suínos (e), como se vê na figura 04. Essas criações são de responsabilidade dos professores e alunos, principalmente dos alunos que ficam encarregados de manter essas produções, eles que plantam, criam e mantém essas produções. 
Figura 04: Produções da Escola Agrícola.

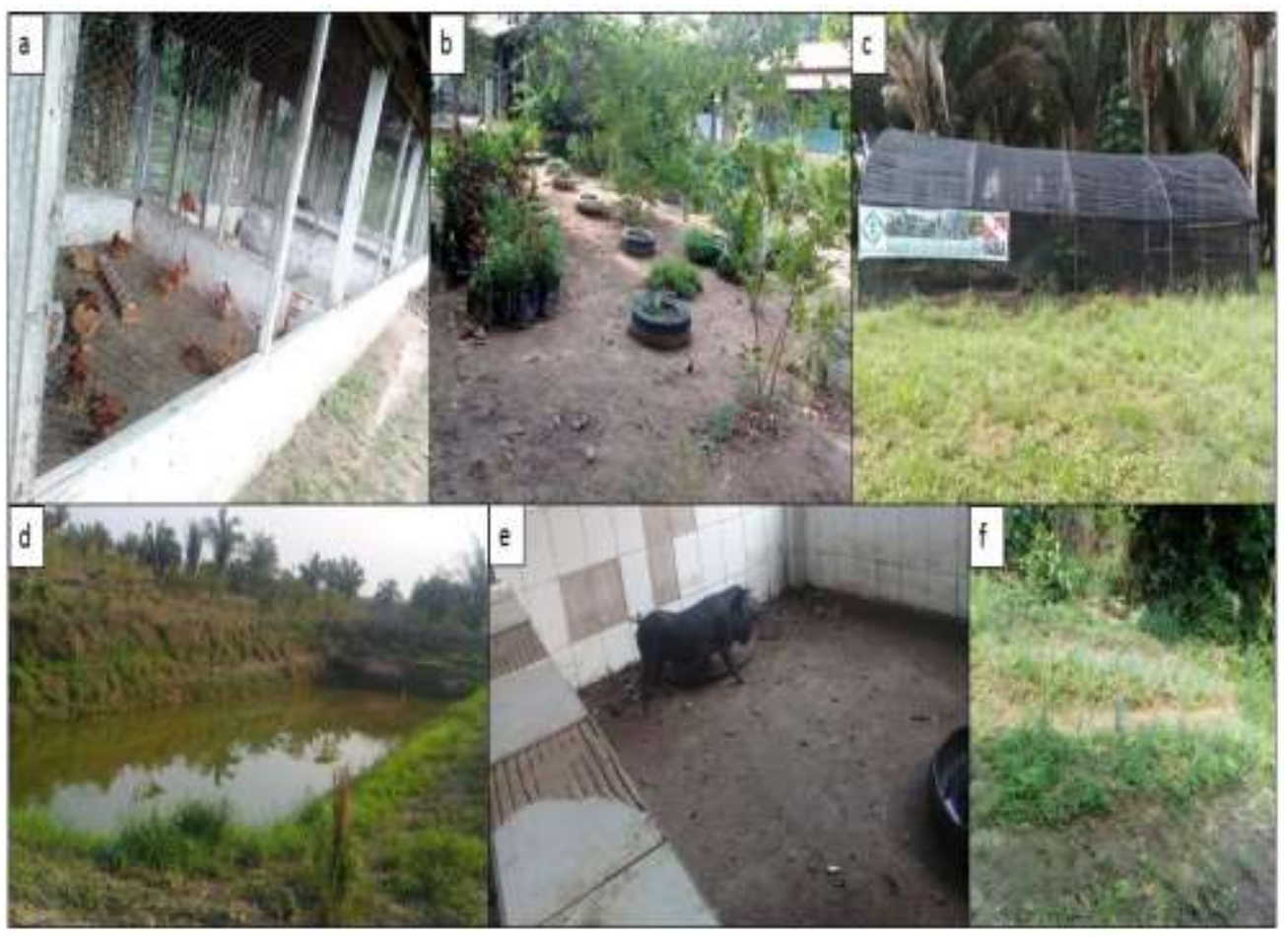

Fonte: Silva, 2017.

\section{MATERIAL E MÉTODOS}

Durante o período de observação do estágio, onde estivemos acompanhando a turma de $9^{\circ}$ ano da escola, foram observadas, além das aulas de geografia, também as disciplinas de Língua Portuguesa, Matemática e Artes. Os professores trabalharam a partir do tema gerador "Feira Livre". Em relação ao tema gerador, o tema é escolhido por sessão, ou seja, a cada sessão há um tema gerador que a partir dele os professores encaminham suas aulas.

Ao chegar à escola, logo no primeiro dia (13/11/17), fomos recepcioandos pelo coordenador pedagógico e ele fez um breve relato de como funciona a organização escolar. Nos deu algumas orientações de como seria nossa participação enquanto estagiários, e entre as explicações disse que os professores são chamados de "monitores", e que à noite, a escola promove um Serão.

Depois, houve uma reunião com a presença de alguns professores da escola e alunos do $8^{\circ}$ e $9^{\circ}$ ano que participaram de alguns trabalhos de campo fora da escola, os quais: viagem para o Rio de Janeiro, viagem para uma comunidade indigena, para a Serra das Andorinhas, e palestra no Departamento Nacional de Infraestrutra de Transportes (DNIT) . Os grupos que 
foram a esses campos, compartilharam suas experiências aos demais alunos, aos professores e estagiários.

No dia 14/11/2017 observamos as aulas de Língua Portuguesa, Geografia e Artes. Os professores trabalharam a partir da realidade vivida dos alunos, ou seja, relacioando suas temáticas de aula com assuntos próximos aos alunos, do cotidiano deles. Os recursos didáticos comumente utilizados pelos professores foram o quadro branco, uso de vídeo em sala de aula, e o livro didático. Só para questão de esclarecimento, a disciplina Língua Portuguesa trabalhou a aula "A feira livre no município de Marabá" com exibição de vídeo, Geografia desenvolveu a aula sobre globalização, onde os alunos formaram grupos para apresentações de seminários em grupo, e foram orientados pelos estagiários, e na disciplina de Artes, a professora desenhou com os alunos uma casa em 3D, que posteriormente eles usaram esse aprendizado para desenhála na produção do mapa mental, cuja aula era a regência de alguns estagiários.

Os professores, em geral, tinham uma boa relação com os alunos, e também uma proximidade com eles, em uma relação amigável que era consequência do método escolar adotado, de regime integral, em que os alunos passam um período considerado na escola, e no caso desses estudantes, em regime de internato durante alguns dias.

No dia 15/11/2017 houve aula de matemática e o professor trabalhou "noções de estatística". No dia 22/11/2017 assisti a regência dos estagiários que acompanharam o $8^{\circ}$ ano, a temática da aula era "sistema de produção e agricultura escolar", primeiro os estagiários ministraram a aula teórica e depois foram para a prática, nessa atividade os alunos teriam que desenvolver um mapa mental a partir do mapa base de Marabá, trazido pelos estagiários.

A regência aconteceu no dia 23/11/2017 em grupo, na turma do $9^{\circ}$ ano, cujo tema da aula foi "Produção Orgânica". A aula se dividiu em dois momentos, em que no primeiro momento aconteceu a aula teórica, com a explanação do tema, e o segundo momento a aula prática, onde demonstramos aos alunos técnicas de produção orgânica.

Durante o primeiro momento da aula (figura 05), perguntamos aos alunos sobre o que eles entendiam sobre produção orgânica, nesse momento, alguns interagiram com os estagiários mostrando conhecimento prévio sobre; já que era um tema da realidade deles, participaram do debate. Em seguida, seguiu-se a aula e durante, foram desenvolvidos alguns conceitos sobre produção orgânica, trabalhando a partir do conceito de lugar, que envolve a realidade dos estudantes, e seu espaço de vivência, a partir da ligação dos alunos com o seu lugar. 
Figura 05: Primeiro momento da regência.

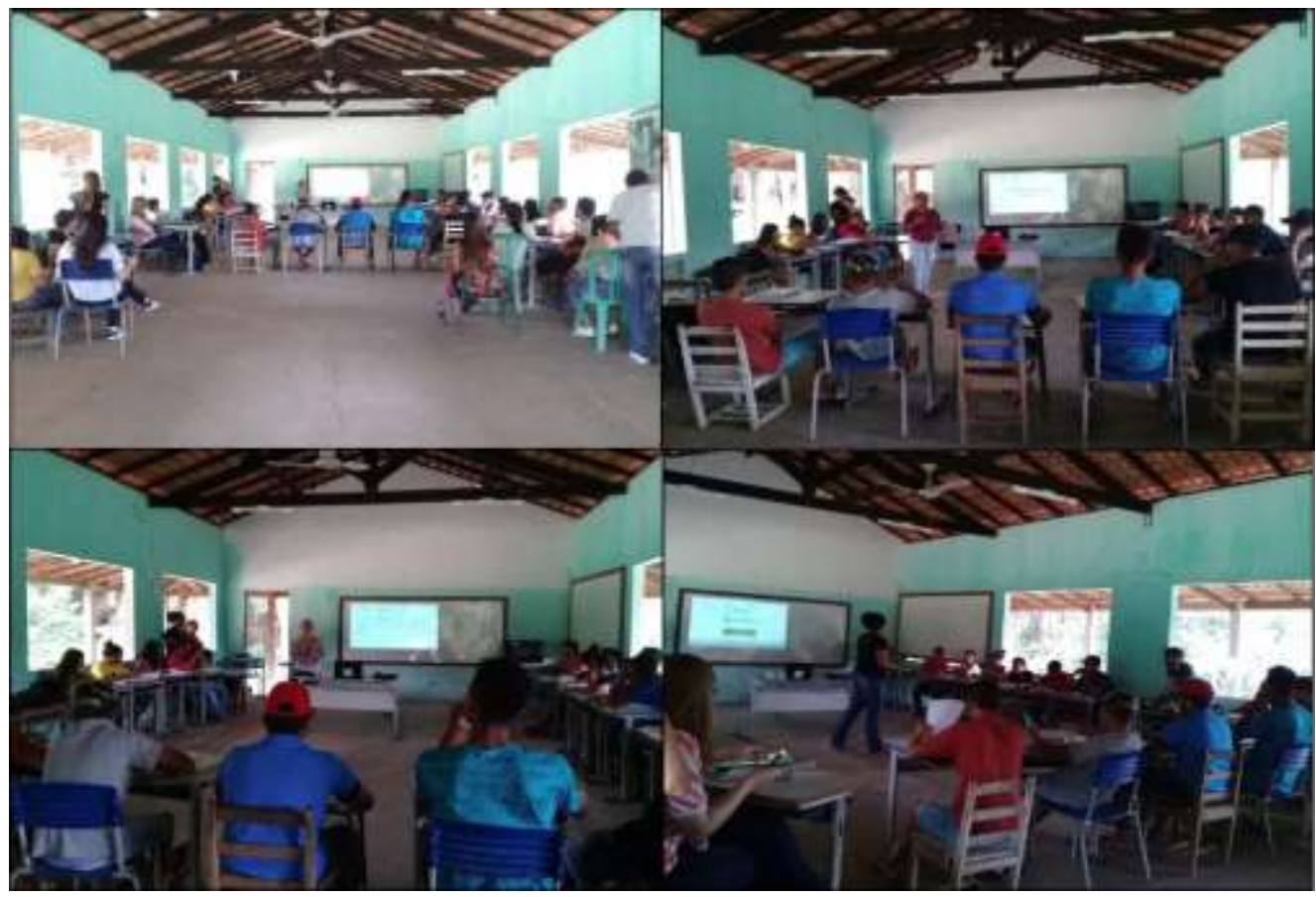

Fonte: Silva, 2017.

Após o desenvolvimento dos conceitos, foi exibido o vídeo "Comida que alimenta", este vídeo era uma animação que tratava sobre a agricultura familiar e como estes produtos eram produzidos, de um modo orgânico e sem uso de agrotóxicos. Mostramos aos alunos como era organizada a agricultura familiar, de modo geral. Após a exibição do vídeo, explorou-se a temática abordada, com os alunos e eles puderam associar com seu modo de produção agrícola em suas comunidades. Em aula, os alunos citaram quais produtos eles e suas famílias produziam, e que eram para consumo familiar e também para venda.

Depois desse primeiro momento, partimos para a prática, em que os alunos foram direcionados até a horta da escola, como mostra a figura 06. 
Figura 06: Aula prática.

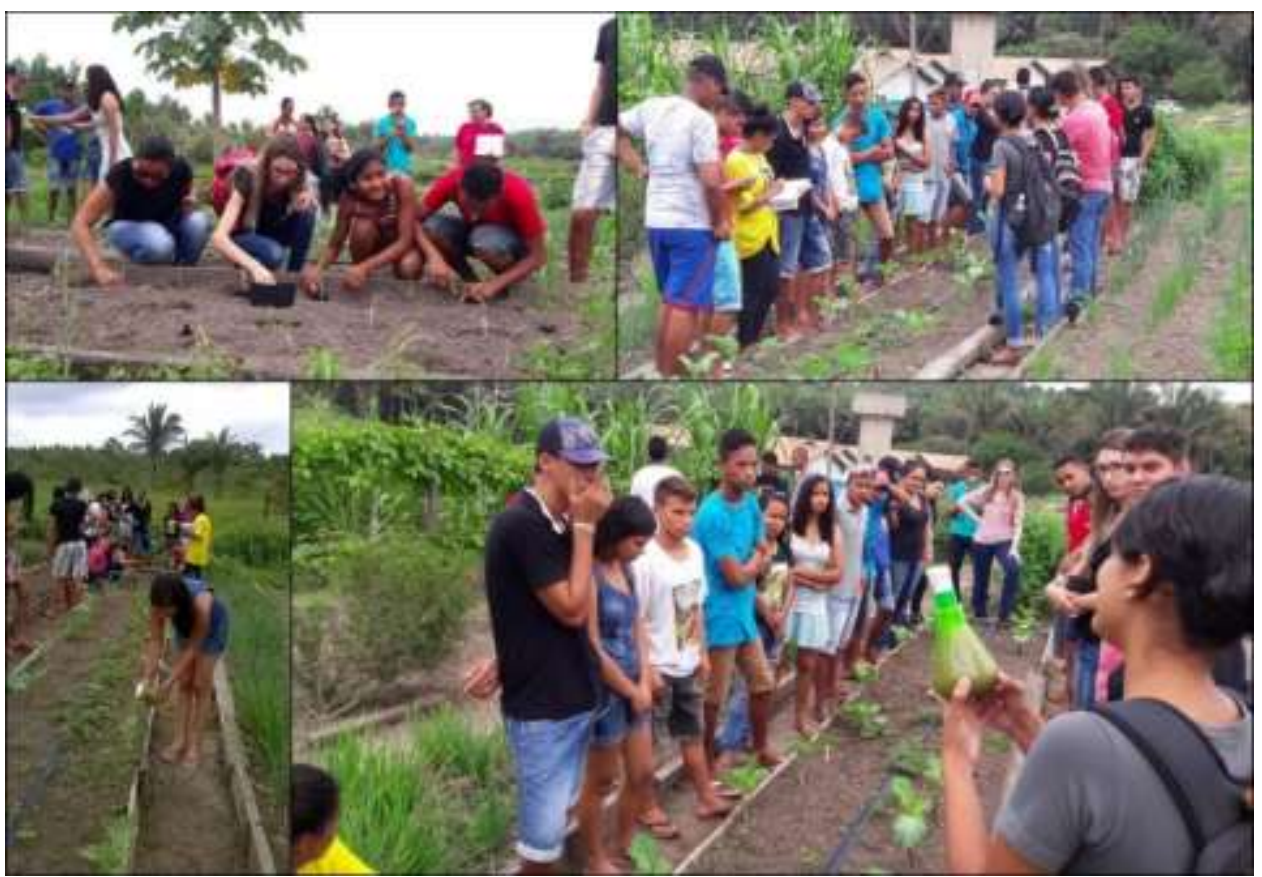

Fonte: Estagiários, 2017.

No segundo momento fomos até a horta da escola com os alunos para demonstrar-lhes técnicas de produção com produtos orgânicos, as técnicas foram adubação com a borra de café e proteção contra insetos com inseticida natural a base de alho. Alguns alunos já demonstraram conhecimento sobre o que apresentamos e deram dicas do que não fazer durante o processo de produção orgânica- como não colocar açúcar na borra de café para que não atraia formigas para a plantação, também demonstraram interesse no que lhes foi mostrado e participaram ativamente desse momento da aula, como podemos ver na imagem acima.

\section{CONSIDERAÇÕES FINAIS}

As escolhas das técnicas de produção orgânica se deram a fim de demonstrar aos alunos que é possível produzir organicamente e sem o uso de agrotóxicos industriais que são extremamente prejudiciais à plantação e à própria saúde, além disso, associamos o tema da nossa aula com o tema gerador "Feira Livre". Desse modo, demonstramos como os alunos podem produzir organicamente para consumo familiar e para venda, e a partir disso que possam tomar ciência de riscos ecológicos que uma má forma de produção causará.

Nesse sentido, os alunos da EFA participaram ativamente da metodologia da regência, e em relação à parte prática, foi a que mais envolveu esses alunos, e eles ficaram muito curiosos 
quanto às técnicas desenvolvidas. Os alunos da EFA, além de manterem uma relação diferenciada com o ambiente escolar, também são muito participativos em aula, e em maioria, interessados e envolvidos com o que está sendo-lhes ensinado.

Ao fazer a associação da metodologia de aula com a prática de vivência dos alunos da EFA, eles puderam participar mais ativamente da metodologia, relatando suas experiências e dando dicas de produção orgânica. Ao ligarmos nossa metodologia à geografia, buscamos fazer-lhes entender os conceitos da agricultura familiar relacionados à realidade desses alunos, que é o campo.

\section{REFERÊNCIAS}

BEZERRA, Amélia $C$. A. O papel da pesquisa e da experiência na formação dos professores de geografia: reflexões a partir dos estágios supervisionados. Revista de Geografia (UFPE) v. 30, n. 1, 2013. p. 40-54.

Escola Família Rural (EFA) de Marabá comemora 20 anos. Disponível em: http://rogeriolmeidafuro.blogspot.com.br/2016/03/escola-familia-rural-efa-de-maraba.html. Acesso em: 22 jan. 2018.

PIMENTA, Selma Garrido e LIMA, Maria Socorro Lucena. Estágio e Docência. 2. ed. São Paulo: Cortez, 2004.

ZIMMERMANN, A; VENDRUSCOLO R; DORNELES S. B. Educação do campo: o processo de implementação da Casa Familiar Rural do Vale do Jaguari (CFR/VJ). In: Geografia Ensino \& Pesquisa. v. 17, n.3 p. 79 -90, set./dez. 2013.

GIL, A.C. Como elaborar projetos de pesquisa. $4^{\mathrm{a}}$ ed. São Paulo: Atlas, 2008. 